\title{
SUSCETIBILIDADE AOS AGENTES QUIMIOTERÁPICOS DE ISOLADOS DE SCHISTOSOMA MANSONI ORIUNDOS DE PACIENTES TRATADOS COM OXAMNIQUINE E PRAZIQUANTEL E NÃO CURADOS
}

\author{
Neusa Araújo, Cecília Pereira de Souza, Liana K. Jannotti Passos, Andrew \\ J.G. Simpson, Emmanuel Dias Neto, Temísio Rodrigues Pereira, Crispim \\ Cerutti Júnior, Filomena Euridice Carvalho de Alencar, Reynaldo \\ Dietze e Naftale Katz
}

\begin{abstract}
Foram estudados dez isolados de Schistosoma mansoni provenientes de pacientes residentes em Itaquara, Babia, Brasil, tratados com oxamniquine e posteriormente com praziquantel, e ainda assim não curados. Caramujos (Biomphalaria glabrata) foram expostos a miracidios provenientes das fezes dos pacientes. Cercárias eliminadas por estes caramujos e por moluscos coletados no peridomicílio dos pacientes foram utilizadas para infecção experimental de camundongos albinos. Os animais infectados foram tratados em dose ünica, tia oral, com oxamniquine $(25,50$ e $100 \mathrm{mg} / \mathrm{kg})$ ou praziquantel $(100,200$ e $400 \mathrm{mg} / \mathrm{kg})$. Foram realizados estudos de análise e comparação de DNA de cercárias de S. mansoni eliminadas pelos caramujos e de vermes adultos recolbidos de camundongos infectados experimentalmente com os isolados dos 10 pacientes $e$ ainda de cercárias de S. mansoni eliminadas por moluscos naturalmente infectados coletados em Itaquara. A cepa $L E$ (mantida rotineiramente no laboratório) foi usada como padrão de comparação da resposta aos agentes esquistossomicidas administrados.As respostas terapêuticas foram significativamente diferentes entre alguns dos isolados embora nâo fosse possinel caracterizar nenbum como resistente. A análise dos perfis de amplificação de DNA nas cercárias e nos vermes adultos dos isolados de S. mansoni demonstrou baixo grau de variabilidade indicando que estes são geneticamente próximos e revelando a ausência de rearranjos globais dentro dos genomas.
\end{abstract}

Palauras-chaves: Schistosoma mansoni. Cepas. Suscetibilidade.

Pacientes com esquistossomose apresentam diferentes respostas ao tratamento específico. Enquanto a maioria dos indivíduos é considerada curada da infecção após o tratamento, alguns ainda continuam eliminando ovos de Schistosoma mansoni nas fezes, mesmo após repetidos tratamentos com uma ou mais drogas quimioterápicas ${ }^{6}{ }^{13}$.

Centro de Pesquisas "René Rachou"/FIOCRUZ/Departamento de Bioquímica e Imunologia/Instituto de Ciências Biológicas, Universidade Federal de Minas Gerais, Belo Horizonte, MG e Núcleo de Doenças Infecciosas/Universidade Federal do Espirito Santo, Vitória, ES, Brasil

Trabalho subvencionado pela Organização Mundial de Saúde, Fundação Nacional de Saúde, Universidade Federal do Espirito Santo e Fundação Oswaldo Cruz.

Endereço para correspondência: $\mathrm{Dr}^{\mathrm{a}}$ Neusa Araújo. Laboratório de Esquistossomose/Centro de Pesquisas René Rachou. Caixa Postal 1743, 30161-970 Belo Horizonte, MG. Recebido para publicação em 09/11/95.
Apesar do grande número de estudos clínicos demonstrando esta não resposta terapêutica, os estudos sobre resistência de cepas de $S$. mansoni aos quimioterápicos ainda são escassos. A primeira evidência com comprovação experimental da resistência do verme a drogas foi publicada em $1973^{12}$. Neste trabalho os autores relatam os resultados do isolamento de uma cepa (WW) de $S$. mansoni, resistente experimentalmente a três drogas (hycanthone, niridazole e oxamniquine) obtida de dois pacientes que não haviam respondido aos tratamentos com hycanthone por 2 vezes e niridazole uma vez. Araújo e cols ${ }^{1}$ estudaram a resposta ao tratamento com niridazole, hycanthone e oxamniquine em camundongos infectados experimentalmente com cepas de $S$. mansoni isoladas de fezes de pacientes tratados e não curados e relataram que, usando o mesmo esquema de tratamento, as diferentes cepas apresentaram respostas significativamente 
Araújo N, Souza CP, Passos LKJ, Simpson AJG, Dias Neto E, Pereira TR, Cerutti Jünior C, Alencar FEC, Dietze R, Katz N. Suscetibilidade aos agentes quimioterápicos de isolados de Schistosoma mansoni oriundos de pacientes tratados com oxaminiquine e praziquantel e não curados. Revista da Sociedade Brasileira de Medicina Tropical 29:467-476, set-0ut, 1996.

diferentes. Resultados de outros isolados de $S$. mansoni considerados resistentes aos agentes esquistossomicidas foram relatados por vários autores 569101125 .

Polimorfismos de DNA detectados por iniciadores aleatórios através da reação em cadeia de polimerase (PCR) tem se mostrado como marcadores genéticos úteis no estudo de uma grande variedade de organismos procariontes e eucariontes ${ }^{23}{ }^{2 i}$. A técnica, denominada AP- PCR, foi usada pela primeira vez em S. mansoni por Dias Neto e cols que mostraram uma variabilidade genética limitada em diferentes isolados desta espécie. Outros autores, usando a mesma metodologia, conseguiram detectar diferenças entre as espécies de Schistosoma ${ }^{714}$ e demonstrar a pequena variabilidade intra específica do $S$. mansoni2. O uso desta técnica em plantas permitiu a identificação de marcadores genéticos de resistência à infecção por patógenos ${ }^{1617}$ demonstrando a utilidade da metodologia na investigação de polimorfismos de DNA relacionados à fenótipos de interesse.

O presente trabalho tem o objetivo de avaliar, experimentalmente, a suscetibilidade de isolados de $S$. mansoni provenientes de pacientes tratados com oxamniquine e praziquantel e não curados e de tentar identificar marcadores genéticos que permitam distinguí-los.

\section{MATERIAL E MÉTODOS}

Pacientes. Foram selecionados para estudo dez pacientes que 45 dias após o tratamento específico continuavam eliminando ovos de $S$. mansoni nas fezes (comprovado pelo método quantitativo de Kato-Katz ). Todos residiam em Itaquara, Bahia, Brasil, com idade variando de 7 a 15 anos e peso entre 19 e $36 \mathrm{~kg}$. A média geométrica do número de ovos por grama de fezes foi de 398,1 $\pm 5,2$ com variação do número de ovos entre 48 e 4248 . O tratamento foi realizado primeiro com oxamniquine na dose única oral de 15 ou $20 \mathrm{mg} / \mathrm{kg}$ para peso superior ou inferior a $30 \mathrm{~kg}$, respectivamente e 5 semanas após com praziquantel na dose única oral de $60 \mathrm{mg} / \mathrm{kg}$. A medicação foi ingerida na presença do médico (RD). Entre os dois tratamentos foi realizado exame de fezes (FPC - formol éter modificado) com teste de viabilidade. A avaliação de cura após o segundo tratamento foi feita também pelo método FPC em três amostras de fezes coletadas em dias diferentes. De cada amostra eram preparadas 4 laminas. Caso as duas primeiras lâminas fossem negativas as duas lâminas subseqüentes eram lidas por um segundo técnico para confirmação do resultado. Todos os resultados positivos foram confirmados pelo teste de eclosão de miracídios. $\mathrm{Na}$ tabela 1 podem ser observados dados referentes a cada un dos pacientes.

Infecção experimental de camundongos. Caramujos (Biomphalaria glabrata) foram expostos a miracídios obtidos das fezes dos pacientes acima mencionados, seis semanas após o último tratamento. Cercárias eliminadas pelos caramujos serviram para infectar camundongos albinos, por via subcutânea com

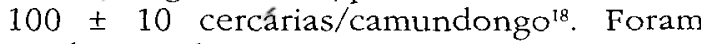
usadas também cercárias eliminadas por caramujos coletados em Itaquara para infecção experimental de camundongos seguindo a mesma metodologia acima citada.

Tabela 1 - Caracteristicas clinicas e parasitológicas dos 10 pacientes estudados que nâo responderam ao tratamento com oxamnitquine e praziquantel.

\begin{tabular}{|c|c|c|c|c|c|c|}
\hline $\begin{array}{l}\text { Paciente } \\
n^{\circ}\end{array}$ & $\begin{array}{l}\text { Idade } \\
\text { (anos) }\end{array}$ & $\begin{array}{l}\text { Peso } \\
(\mathrm{kg})\end{array}$ & $\begin{array}{l}\text { No de ovos por grama } \\
\text { de fezes (Kato-Katz) } \\
\text { antes do tratamento }\end{array}$ & $\begin{array}{l}\text { Oxa } \\
(\mathrm{mg})\end{array}$ & $\begin{array}{l}\text { Pzq } \\
(\mathrm{mg})\end{array}$ & $\begin{array}{c}\text { Teste de eclosão de miracidios } \\
\text { após o tratamento }\end{array}$ \\
\hline 8 & 11 & 29 & 72 & 580 & 1740 & + \\
\hline 20 & 11 & 30 & 624 & 600 & 1800 & + \\
\hline 29 & 10 & 29 & 48 & 580 & 1740 & + \\
\hline 99 & 9 & 20 & 264 & 400 & 1200 & + \\
\hline 126 & 10 & 29 & 96 & 580 & 1740 & + \\
\hline 162 & 12 & 22 & 96 & 440 & 1320 & + \\
\hline 256 & 15 & 36 & 1272 & 540 & 2160 & + \\
\hline 262 & 7 & 19 & 4248 & 380 & 1140 & + \\
\hline 290 & 10 & 25 & 4224 & 500 & 1500 & + \\
\hline 294 & 10 & 27 & 768 & 540 & 1620 & + \\
\hline
\end{tabular}

Pzq = praziquantel : oxa $=$ oxamniquine 
Araüjo N, Souza CP, Passos LKJ, Simpson AJG, Dias Neto E, Pereira TR, Cerutti Jünior C, Alencar FEC, Dietze $R$, Katz $N$. Suscetibilidade aos agentes quimioterápicos de isolados de Schistosoma mansoni oriundos de pacientes tratados com oxaminiquine e praziquantel e não curados. Revista da Sociedade Brasileira de Medicina Tropical 29:467-476, set-out, 1996.

Terapêutica experimental de camundongos. Quarenta e cinco dias após a infecção os camundongos foram separados em grupos e tratados por via oral e em dose única com oxamniquine $(25,50$ e $100 \mathrm{mg} / \mathrm{kg})$ ou praziquantel $(100,200$ e $400 \mathrm{mg} / \mathrm{kg})$. Foram realizados, paralelamente, experimentos seguindo o mesmo esquema de tratamento utilizando-se camundongos infectados com $100 \pm 10$ cercárias da cepa LE de $S$. mansoni. (mantida rotineiramente em nossos laboratórios e usada como padrão em estudos de resistência) para efeito de comparação e avaliação da atividade das drogas. Um grupo de camundongos infectados e não tratados funcionou como controle da infecção nos experimentos realizados para cada isolado. Quinze dias após o tratamento, os camundongos foram sacrificados por fratura cervical e os vermes localizados no mesentério e fígado foram recolhidos por perfusão. Os fígados dos camundongos foram esmagados entre duas placas de vidro e examinados em microscópio estereoscópico para determinação do número de vermes mortos. Fragmentos do intestino delgado, esmagados entre lâmina e lamínula foram observados ao microscópio para avaliação do oograma, que foi considerado alterado na ausência de um ou mais estágios de ovos imaturos ${ }^{18}$. A eficácia da droga foi calculada baseando-se no número de vermes vivos recolhidos dos animais dos grupos controles e tratados, usando-se a seguinte equaçã $\mathrm{O}^{15}$ :

$$
\text { Eficácia }=\frac{a-b}{a} \times 100
$$

onde $\mathrm{a}=$ número médio de vermes vivos recolhidos dos animais dos grupos controles e $\mathrm{b}=$ número médio de vermes vivos recolhidos dos grupos tratados..Foram realizados cálculos das doses responsáveis por 50 e $90 \%$ de eficácia $\left(\mathrm{DE}_{50}\right.$ e $\mathrm{DE}_{90}$, respectivamente) de cada droga para cada isolado utilizando-se gráficos, onde as percentagens de eficácia foram posicionadas no eixo y e a dose total $(\mathrm{mg} / \mathrm{kg})$ no eixo $\mathrm{x}$.

Para determinar a dose responsável por $50 \%$ de alteração do oograma (DO 50 ) de cada droga para cada isolado, foi feito um gráfico, onde a percentagem de alteração do oograma foi posicionada no eixo y e a dose total ( $\mathrm{mg} / \mathrm{kg}$ ) no eixo $\mathrm{x}$.
Preparação do DNA. A extração do DNA foi feita de acordo com a técnica descrita anteriormente por Simpson e cols ${ }^{21}$. Cercárias e vermes adultos foram suspensos em $50 \mathrm{mM}$ de Tris HCL, $100 \mathrm{mM}$ de NaCl, 50nM de EDTA, SDS a $0,5 \%$, em pH 8,0 e digeridos com $50 \mathrm{~g} / \mathrm{ml}$ de proteinase $\mathrm{K}$ por 2 horas a $37^{\circ} \mathrm{C}$. A seguir foi feita extração com fenol/clorofórmio e precipitação com etanol. O DNA foi ressuspenso em $10 \mathrm{mM}$ de Tris HCL, $1 \mathrm{mM}$ de EDTA em pH 8,0 e sua concentração foi determinada por comparação com padrões conhecidos, através de eletroforese em gel agarose a $2 \%$ corado com brometo de etídio.

Análise de polimorfismos de DNA amplificado aleatoriamente. A análise dos perfis de amplificação de DNA foi feita com o DNA de cercárias e vermes aduitos provenientes de cada isolado e de cercárias de caramujos naturalmente infectados (Itaquara-Bahia), comparados com a cepa LE. Os perfis foram obtidos com os iniciadores: 3303 (5'-TCACGATGCA-3'), GATA4 (5'-GATAGATAGATAGATA-3'), 3307 (5'AGTGCTACGT-3') e 3306 (5'- AGCATCTGTT-3'). Cada reação de amplificação foi feita em um volume final de $10 \mu \mathrm{l}$ contendo 0,8 unidades de Taq DNA polimerase (Cenbiot RS, Brasil), $200 \mathrm{mM}$ de cada dNTP, 1,5mM de $\mathrm{MgCl} 2,50 \mathrm{mM}$ de $\mathrm{KCl}, 10 \mathrm{mM}$ de Tris- $\mathrm{HCl}, \mathrm{pH} 8,5$, juntamente com 6,4 pmoles de iniciador e 1,0ng do DNA molde. Esta reação foi coberta com $20 \mu$ le óleo mineral seguindo-se uma desnaturação inicial a $95^{\circ} \mathrm{C}$ por 5 minutos. À seguir foi submetida a 2 ciclos observando as seguintes temperaturas e tempos: $30^{\circ} \mathrm{C}$ por 2 minutos para anelamento, $72^{\circ} \mathrm{C}$ por 1 minuto para extensão e $95^{\circ} \mathrm{C}$ por 5 minutos para desnaturação seguido por 33 ciclos onde o passo anelamento foi alterado para $40^{\circ} \mathrm{C}$. No ciclo final o passo de extensão foi de 5 minutos. Após amplificação, $3 \mu \mathrm{l}$ da reação foram misturados com 0,6 ul do tampão de amostra $6 \mathrm{X}$ concentrada $(0,25 \%$ de azul de bromofenol, $0,25 \%$ de xileno cianol e $30 \%$ de glicerol) e submetido à eletroforese em gel de poliacrilimida à $4 \%$. Os géis foram fixados com $10 \%$ de etanol-0,5\% de ácido acético por 20 minutos e as bandas de DNA visualizadas com o auxílio de $0,2 \%$ de nitrato de prata por 30 minutos e redução com NaOH $0,75 \mathrm{M}$ formaldeído $0.1 \mathrm{M}$ por 10 minutos como previamente descrito ${ }^{19}$.

Análise estatística. Para avaliar a homogeneidade da infecção entre os grupos 
Araújo N, Souza CP, Passos LKJ, Simpson AJG, Dias Neto E, Pereira TR, Cerutti Jünior C, Alencar FEC, Dietze $R$, Katz $N$. Suscetibilidade aos agentes quimioterápicos de isolados de Schistosoma mansoni oriundos de pacientes tratados com oxaminiquine e praziquantel e não curados. Revista da Sociedade Brasileira de Medicina Tropical 29:467-476, set-out, 1996.

tratados e controles, a comparação da média de vermes e da média de vermes mortos no fígado, o significado estatístico da alteração do oograma e as diferenças de eficácia entre os diversos isolados e a cepa LE foram realizados os seguintes testes estatísticos: análise de variância, qui-quadrado de Pearson e teste t de Student, sendo considerado o valor mínimo de significância de $\mathrm{p} \leq 0,05^{20}$.

\section{RESULTADOS}

Nas Tabelas 2 e 3 podem ser vistos os resultados obtidos após a administração de oxamniquine ou praziquantel nos camundongos infectados experimentalmente com os diversos isolados de $S$. mansoni bem como com a cepa LE, e as respectivas percentagens de eficácia. Com oxamniquine $(100 \mathrm{mg} / \mathrm{kg})$, a percentagem de vermes mortos no fígado variou de 23,5 (isolado 8) a 92,4 (isolado 29 ). Em relação à alteracão do oograma, não houve diferença significativa. Quando foi administrado o praziquantel na dose de $400 \mathrm{mg} / \mathrm{kg}$, houve alteração do oograma em $100 \%$ dos animais tratados, e a percentagem de vermes mortos no fígado variou de 53,1 (isolado 99) a 98,0 (isolado do campo).

As percentagens de eficácia das duas drogas usadas podem ser vistas nas Tabelas 2 e 3. O isolado 008 mostrou ser o menos suscetivel à oxamniquine $(32,8,37,6$ e $48,0 \%$ de eficácia quando as doses usadas foram 25 , 50 e $100 \mathrm{mg} / \mathrm{kg}$ ) e os isoladas 29 e 99 foram os mais suscetíveis à esta mesma droga apresentando eficácia de 92,4 e 91,5\%, respectivamente, quando foi usada a dosagem

Tabela 2 - Atividade esquistossomicida de oxamniquine, dose única. via oral en camundongos infectados experimentalmente com cercárias de diuersos isolados e a ceta LE de Scbistosoma mansoni sacrificados 15 dias apos o tratamento

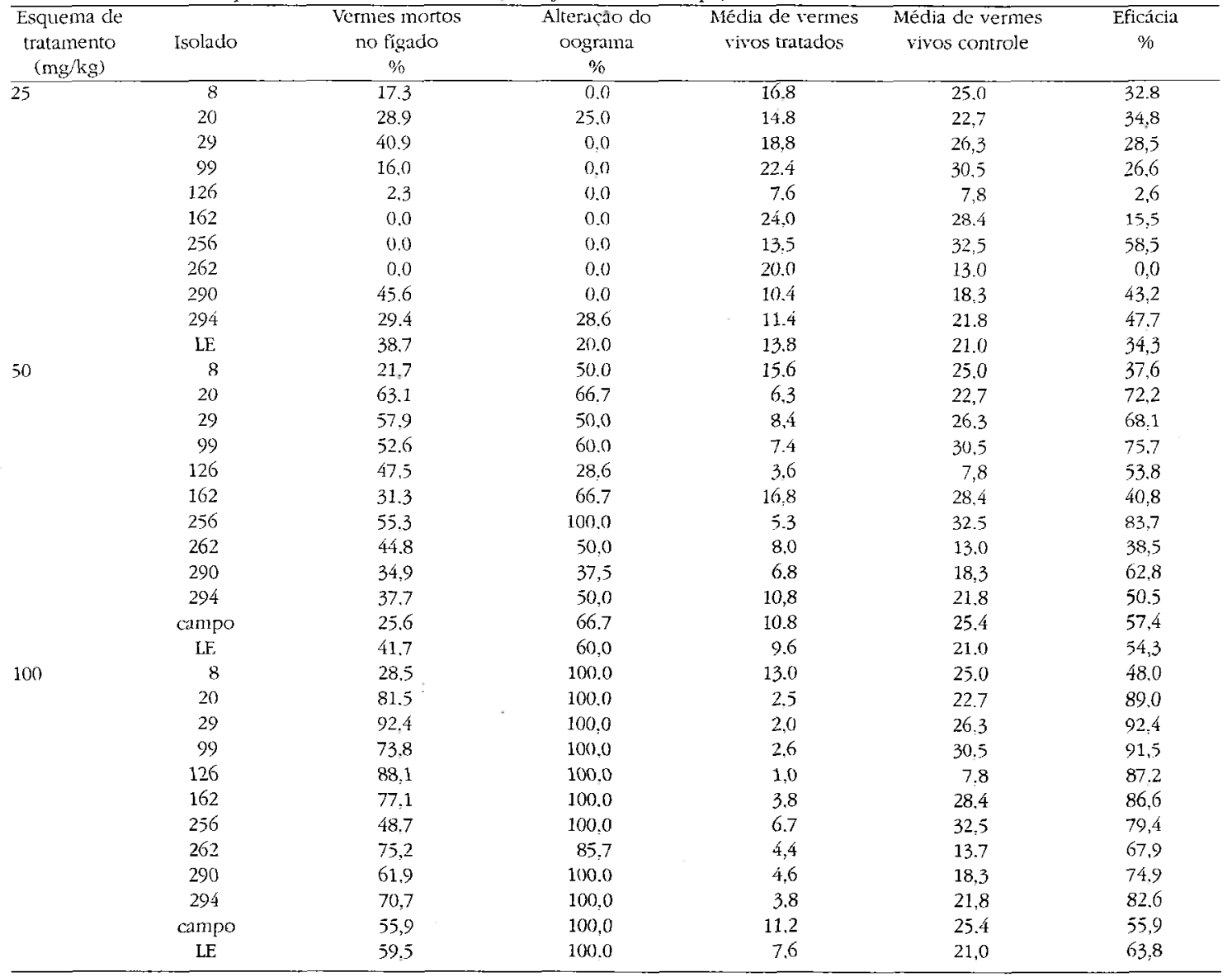


Araújo N, Souza CP, Passos LKJ, Simpson AJG, Dias Neto E, Pereira TR, Cerutti Júnior C, Alencar FEC, Dietze $R$, Katz N. Suscetibilidade aos agentes quimioteräpicos de isolados de Schistosoma mansoni oriundos de pacientes tratados com oxaminiquine e praziquantel e não curados. Revista da Sociedade Brasileira de Medicina Tropical 29:467-476, set-out, 1996.

Tabela 3 - Atividade esquistossomicida do praziquantel, dose única, via oral, em camundongos infectados experimentalmente com cercárias de diversos isolados e a cepa LE de Scbistosoma mansoni, sacrificados 15 dias após o tratamento

\begin{tabular}{|c|c|c|c|c|c|c|}
\hline $\begin{array}{c}\text { Esquema de } \\
\text { Tratamento } \\
(\mathrm{mg} / \mathrm{kg})\end{array}$ & Isolado & $\begin{array}{c}\text { Vermes mortos } \\
\text { no figado } \\
\%\end{array}$ & $\begin{array}{c}\text { Alteraçäo do } \\
\text { oograma } \\
\%\end{array}$ & $\begin{array}{l}\text { Média de vermes } \\
\text { vivos tratados }\end{array}$ & $\begin{array}{l}\text { Média de vermes } \\
\text { vivos controle }\end{array}$ & $\begin{array}{c}\text { Eficácia } \\
\%\end{array}$ \\
\hline \multirow[t]{11}{*}{100} & 8 & 2,2 & 25,0 & 13,0 & $\overline{25,0}$ & 48,0 \\
\hline & 20 & 2,0 & 0,0 & 20,0 & 22,7 & 11,9 \\
\hline & 29 & - & - & - & - & - \\
\hline & 99 & 16,1 & 0,0 & 9,0 & 30.5 & 70,5 \\
\hline & 126 & 20,0 & 0,0 & 2,1 & 7,8 & 73,1 \\
\hline & 162 & 3,5 & 0,0 & 19,1 & 28,4 & 32,7 \\
\hline & 256 & 44,9 & 0,0 & 13,5 & 32,5 & 58,5 \\
\hline & 262 & 57,0 & 20,0 & 6,8 & 13,0 & 47,7 \\
\hline & 290 & 31,1 & 50.0 & 8,8 & 18,3 & 51,9 \\
\hline & 294 & 25,0 & 0,0 & 15,1 & 21,8 & 30,7 \\
\hline & $\mathrm{LE}$ & 7,6 & 33,3 & 21.3 & 21,0 & 0,0 \\
\hline \multirow[t]{12}{*}{200} & 8 & 24,3 & 50,0 & 20,3 & 25,0 & 18,8 \\
\hline & 20 & 56,0 & 50,0 & 11,5 & 22,7 & 49,3 \\
\hline & 29 & 48,7 & 33,3 & 15,5 & 26,3 & 41,1 \\
\hline & 99 & 24,1 & 40,0 & 16,8 & 30,5 & 44,9 \\
\hline & 126 & 51,6 & 50,0 & 3,8 & 7.8 & 51,3 \\
\hline & 162 & 8,5 & 50,0 & 32,5 & 28,4 & 0,0 \\
\hline & 256 & 30,4 & 33,3 & 21,3 & 32,5 & 34,5 \\
\hline & 262 & 75,7 & 75.0 & 4,3 & 13,0 & 66,9 \\
\hline & 290 & 17,0 & 40,0 & 4,8 & 18,3 & 73,8 \\
\hline & 294 & 26,4 & 30,0 & 17,1 & 21,8 & 21,6 \\
\hline & campo & 16,7 & 50,0 & 6,0 & 25,4 & 76,4 \\
\hline & LE & 16,7 & 60,0 & 10,0 & 21,0 & 52,4 \\
\hline \multirow[t]{12}{*}{400} & 8 & 39.1 & 100,0 & 17,4 & 25,0 & 30,4 \\
\hline & 20 & 39.3 & 100,0 & 5,4 & 22,7 & 76,2 \\
\hline & 29 & 36,8 & 100,0 & 6,0 & 26,3 & 77.2 \\
\hline & 99 & 50,3 & 100.0 & 9,0 & 30,5 & 70,5 \\
\hline & 126 & 67,8 & 100,0 & 3,0 & 7,8 & 61,5 \\
\hline & 162 & 50,6 & 100,0 & 13.0 & 28.4 & 54,2 \\
\hline & 256 & 44,8 & 100,0 & 19,3 & 32,5 & 40,6 \\
\hline & 262 & 84,1 & 100,0 & 3,6 & 13,7 & 73,7 \\
\hline & 290 & 85,7 & 100,0 & 1,8 & 18,3 & 90,2 \\
\hline & 294 & 56,3 & 100,0 & 7,4 & 21,8 & 66,1 \\
\hline & campo & 86.0 & 100.0 & 3,4 & 25,4 & 86,6 \\
\hline & LE & 44,3 & 100,0 & 11.2 & 21,0 & 46,7 \\
\hline
\end{tabular}

mais alta. Quando foi administrado o praziquantel, o isolado 8 mostrou ser o menos sensivel pois com a dosagem de $400 \mathrm{mg} / \mathrm{kg}$ apresentou $30,4 \%$ de eficácia e os isolados 290 e de caramujos naturalmente infectados, coletados em Itaquara, foram os mais sensiveis apresentando 90,2 e $86,6 \%$ de eficácia, respectivamente, quando a dosagem usada foi de $400 \mathrm{mg} / \mathrm{kg}$.

Os resultados da análise de variância da média de vermes e da média de vermes mortos no figado comparados entre camundongos infectados pelos diferentes isolados e a cepa $L E$ de $S$. mansoni após tratamento com oxamniquine $(100 \mathrm{mg} / \mathrm{kg})$ ou praziquantel $(400 \mathrm{mg} / \mathrm{kg})$ podem ser vistos na Tabela 4 . Os isolados 99 e 20 nâo aparecem nesta tabela porque a análise de variância mostrou que a infecção não foi homogênea, não podendo, portanto, seus resultados serem avaliados por este método estatístico. Com oxamniquine, apresentaram diferenças estatisticamente significativa, a média de vermes no isolado 126 e a média de vermes mortos no fígado no isolado 8. Após a administração de praziquantel, foram observadas diferenças estatisticamente significativas na média de vermes do isolado 126 e na média de vermes mortos no fígado nos isolados dos caramujos do campo e 262. Os valores encontrados para as $\mathrm{DE}_{50}, \mathrm{DE}_{90}$, e $\mathrm{DO}_{50} \mathrm{em} \mathrm{mg} / \mathrm{kg}$ podem ser vistos na Tabela 5. Com oxamniquine, a $\mathrm{DE}_{50}$ variou de 30 (isolado 20 ) à $100 \mathrm{mg} / \mathrm{kg}$ (isolado 8), sendo que o isolado 008 mostrou diferença estatísticamente significativa. A DE $\mathrm{O}_{0}$ variou de 88 (isolado 29) a $250 \mathrm{mg} / \mathrm{kg}$ (isolado 8) sendo 
Araújo $N$, Souza CP, Passos LKJ, Simpson AJG, Dias Neto E, Pereira TR, Cerutti Jünior C, Alencar FEC, Dietze R, Katz N. Suscetibilidade aos agentes quimioterápicos de isolados de Schistosoma mansoni oriundos de pacientes tratados com oxaminiquine e praziquantel e não curados. Revista da Sociedade Brasileira de Medicina Tropical 29:467-476, set-out, 1996. Tabela 4 - Média de vermes recuperados e média de vermes mortos no figado entre camundongos infectados por diferentes isolados e pela
cepa LE de Schistosoma mansoni

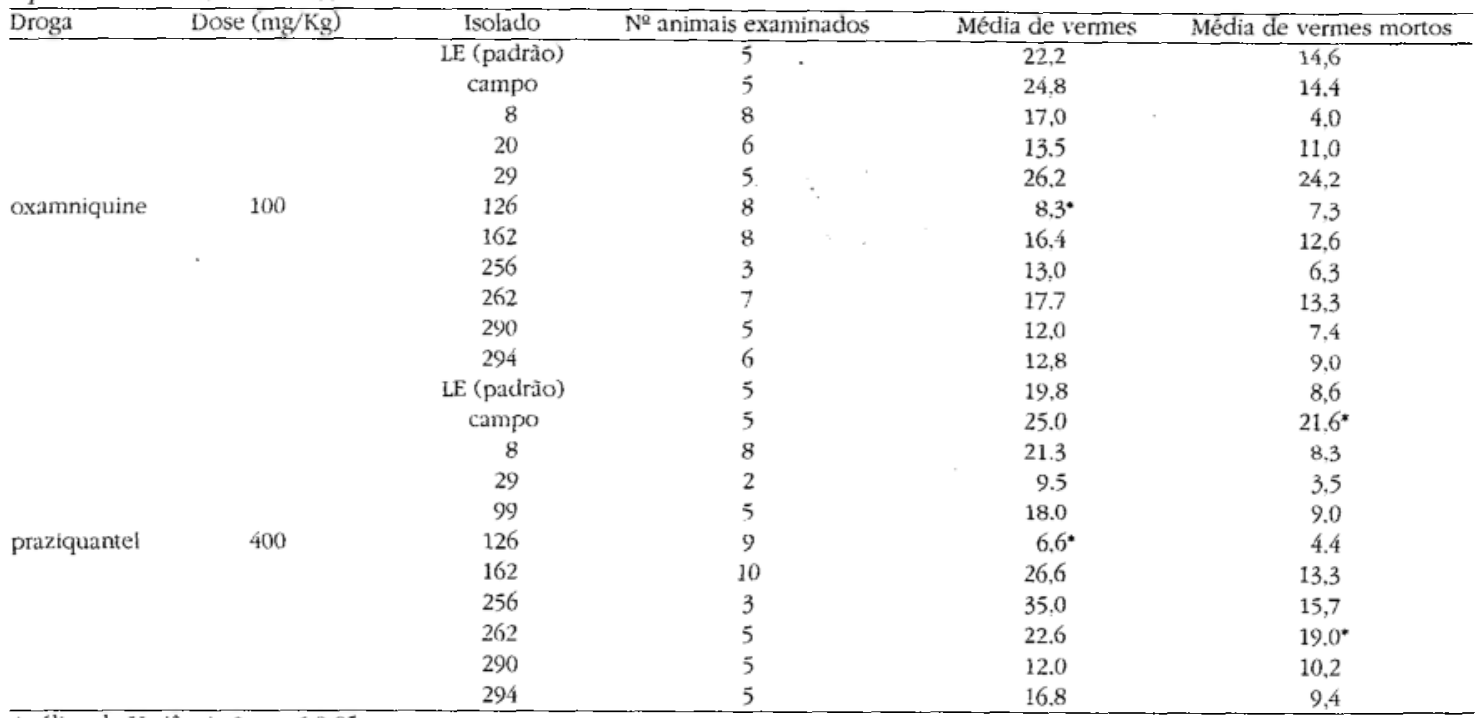

Análise de Variância $=\bar{p} \leq \overline{0,05}$

Tabela 5 - Valores das $D E_{50} D E_{90}$ e $D O_{50}(e m \mathrm{mg} / \mathrm{Kg})$ de drogas esquistossomictdas nos diferentes isolados e na cepa $L E$ de $\mathrm{Schistosoma}$ manson

\begin{tabular}{|c|c|c|c|c|}
\hline Droga & Isolado & $\overline{D E}_{50}$ & $\overline{\mathrm{DE}}_{90}$ & $\overline{\mathrm{DO}}_{50}$ \\
\hline \multirow{8}{*}{ oxamniquine } & 8 & $100^{\circ}$ & $250^{4}$ & 50 \\
\hline & 20 & 30 & 100 & 33 \\
\hline & 29 & 40 & 88 & 50 \\
\hline & 99 & 37 & 85 & 45 \\
\hline & 126 & 44 & 120 & 57 \\
\hline & 162 & 57 & 137 & 45 \\
\hline & 256 & 40 & 168 & 33 \\
\hline & 262 & 72 & 133 & 50 \\
\hline \multirow{16}{*}{ praziquantel } & 290 & 40 & 113 & 55 \\
\hline & 294 & 50 & 107 & 50 \\
\hline & campo & 40 & 160 & 43 \\
\hline & LE & 46 & 113 & 40 \\
\hline & 8 & $640^{\circ}$ & $2220^{*}$ & 200 \\
\hline & 20 & 240 & 624 & 200 \\
\hline & 29 & 267 & 800 & 220 \\
\hline & 99 & 233 & 800 & 230 \\
\hline & 126 & 167 & 720 & 200 \\
\hline & 162 & 360 & 1522 & 200 \\
\hline & 256 & 300 & 818 & 230 \\
\hline & 262 & $110^{*}$ & 406 & $150^{*}$ \\
\hline & 290 & $92^{\circ}$ & 400 & $160^{*}$ \\
\hline & 294 & 227 & 643 & 230 \\
\hline & campo & $50^{*}$ & 526 & 200 \\
\hline & LE & 200 & 592 & 200 \\
\hline
\end{tabular}

$\bar{*} 0.05$

este último resultado estatísticamente significativo. Quando foi administrado o praziquantel, a $\mathrm{DE}_{50}$ variou de 50 (isolado do campo) a $640 \mathrm{mg} / \mathrm{kg}$ (isolado 8) apresentando diferenças estatísticamente significativas os isolados 8, 262, 290 e aquele proveniente dos caramujos do campo e a $\mathrm{DE}_{90}$ variou de 380 (isolado 20) à 2220 (isolado 8), sendo este último resultado estatísticamente significativo. A $\mathrm{DO}_{50}$ variou de 33 a $57 \mathrm{mg} / \mathrm{kg}$ para 
Araújo N, Souza CP, Passos LKJ, Simpson AJG, Dias Neto E, Pereira TR, Cerutti Jünior C, Alencar FEC, Dietze $R$, Katz $N$. Suscetibilidade aos agentes quimioterápicos de isolados de Schistosoma mansoni oriundos de pacientes tratados com oxaminiquine e praziquantel e não curados. Revista da Sociedade Brasileira de Medicina Tropical 29:467-476, set-out, 1996.

oxamniquine e de 150 a $230 \mathrm{mg} / \mathrm{kg}$ no caso do praziquantel. Dois resultados foram estatisticamente significativos, a saber: isolados 262 e 290 quando a droga administrada foi o praziquantel.

Quando os perfis de amplificação de isolados oriundos de pacientes foram comparados aos perfis de isolados de moluscos naturalmente infectados da região ou à cepa LE, não foi observado nenhum polimorfismo de DNA que pudesse ser relacionado a alguma característica específica em qualquer das amostras estudadas. Quando o padrão de bandeamento de DNA foi analisado (Figura 1) observou-se um alto grau de compartilhamento de bandas.

$A$ ausência de polimorfismos característicos também foi observada quando o DNA derivado de cercárias ou vermes adultos de isolados foram comparados aos mesmos estágios da cepa LE (Figura 2) indicando a inexistência de rearranjos genéticos globais, que poderiam ser relacionados à resistência a drogas.

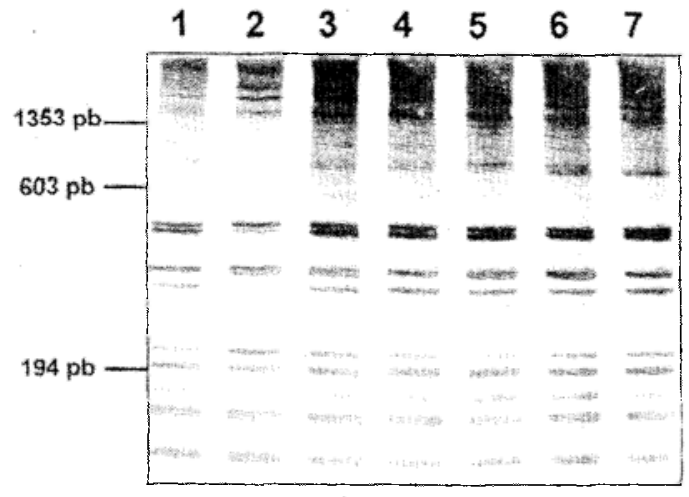

Figura 1 - Gel de poliacrilamida a $4 \%$ corado pela prata mostrando o perfil de RAPD derivado de um pool de cercáriasde S. mansoni eliminadas de B. glabrata infectados com miracidios provenientes das fezes dos pacientes 008 (Linda 1), 029 (Linda 2), 162 (Linda 3), 126 (Linda 4), 290 (Linda 5), caramujos naturalmente infectados (linha 6) ou a ceba LE (linha 7). O iniciador usado foi GATA4. O tamanbo molecular - TH ( em pares de bases - $p b$ ) estâ indicado â esquerda da figura.

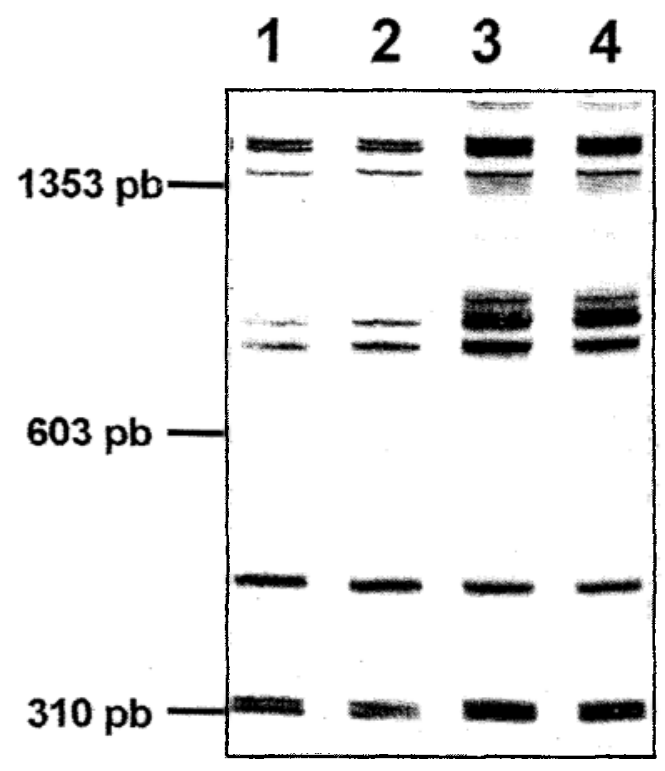

Figura 2 - Gel de poliacrilamida a $4 \%$ corado pela prata mostrando o perfil de RAPD derivado de vermes adultos (linbas 1 e 2) e de cercárias (linhas 3 e 4) de $\mathrm{S}$. mansoni com o iniciador 3303. Linhas 1 e 3 - material biológico derivado do paciente 262 . Linhas 2 e 4 material biológico derivado da cepa $L E$. O tamanbo molecular - TM (em pares de bases - $p b$ ) está indicado à esquerda da figura.

\section{DISCUSSÃO}

Neste trabalho foi avaliada a suscetibilidade ao tratamento quimioterápico experimental de 10 isolados de $S$. mansoni provenientes de pacientes esquistossomóticos, tratados por duas vezes sendo uma com oxamniquine e outra com praziquantel, e não curados, e um isolado proveniente de caramujos coletados no peridomicílio dos pacientes, paralelamente à cepa LE, de suscetibilidade conhecida, para efeito de comparação.

Os resultados obtidos após a administração dos esquistossomicidas mostram que os isolados responderam diferentemente ao tratamento, alguns apresentando diferenças estatisticamente significativas no número médio de vermes mortos no fígado, percentagem de alteração do oograma, $\mathrm{DE}_{50}, \mathrm{DE}_{90}$ e $\mathrm{DO}_{50}$, mas no conjunto não foram apresentadas diferenças que pudessem caracterizá-los como resistentes. 
Araújo N, Souza CP, Passos LKJ, Simpson AJG, Dias Neto E, Pereira TR. Cenutti Jünior C, Alencar FEC, Dietze $R$, Katz $N$. Suscetibilidade aos agentes quimioterápicos de isolados de Schistosoma mansoni oniundos de pacientes tratados com oxaminiquine e praziquantel e não curados. Relista da Sociedade Brasileira de Medicina Tropical 29:467-476, set-out, 1996.

Katz e cols ${ }^{12}$ demonstraram, pela primeira vez na literatura, que uma cepa isolada de dois pacientes tratados 2 vezes com hycanthone e uma vez com niridazole, apresentou baixa suscetibilidade ao hycanthone, niridazole e oxamniquine quando estudada experimentalmente. Araújo e cols ${ }^{1}$ encontraram resistência experimental aos tratamentos com niridazole, hycanthone e oxamniquine em cepas originárias de pacientes tratados com drogas esquistossomicidas e não curados e em outras provenientes de pacientes que nunca haviam sido tratados.

Yeang e cols ${ }^{25}$ mostraram que as $\mathrm{DL}_{50}$, em $\mathrm{mg} / \mathrm{kg}$ de oxamniquine, para os vermes machos foi dez vezes maior em duas de três cepas resistentes testadas, quando comparadas a 4 cepas reconhecidamente sensiveis. Drescher e cols ${ }^{9}$ estudaram a suscetibilidade de 4 isolados (BH, MAP, MPR-1 e K) usando esquemas múltiplos de hyanthone, niridazole, oxamniquine e praziquantel. A discussão dos resultados foi baseada na $\mathrm{DE}_{50}(50 \%$ de eficácia). A cepa BH foi suscetível à todas as drogas usadas. $\mathrm{O}$ isolado $\mathrm{K}$ foi resistente ao niridazole; MPR-1 foi resistente à oxamniquine e o isolado MAP, citado na literatura como resistente ao hycanthone e oxamniquines apresentou valores da $\mathrm{DE}_{50} 5$ e 10 vezes maiores que aqueles apresentados pelo isolado $\mathrm{BH}$, respectivamente, confirmando sua resistência. Fallon e Doenhoff ${ }^{10}$ estudaram a resistência de infecções esquistossomóticas induzida pelo tratamento com doses múltiplas subcurativas de praziquantel ou oxamniquine, As drogas foram administradas a camundongos portadores de infecção no estágio de verme adulto no inicio da postura ( 35 e 37 dias após infecção, respectivamente). Noventa e três por cento dos vermes selecionados para resistência ao praziquantel sobreviveram à 3 doses de $300 \mathrm{mg} / \mathrm{kg}$ da mesma droga administrada entre os dias 28 e 37 da infecção após 7 gerações mas somente $13 \%$ dos vermes sobreviveram à 3 doses de $200 \mathrm{mg} / \mathrm{kg}$ de oxamniquine administrada no mesmo período após infecção. Os vermes selecionados para resistência à oxamniquine foram completamente resistentes a 3 doses de $200 \mathrm{mg} / \mathrm{kg}$ da mesma droga após a sexta geração, porém somente $26 \%$ sobreviveram a 3 doses de $300 \mathrm{mg} / \mathrm{kg}$ de praziquantel. Os autores concluíram que o $S$. mansoni pode tornar-se resistente aos agentes esquistossomicidas, num espaço de tempo relativamente curto, quando submetido a diversos tratamentos, mas que a resistência cruzada entre praziquantel e oxamniquine não ocorre.

Marcadores genéticos de resistência à drogas em $S$. mansoni foram estudados por Brindley e cols ${ }^{3}$ que demonstraram alteraçòes no gene $18 \mathrm{~S}$ de RNA ribosomal relacionadas com a indução experimental de resistência no tratamento com hycanthone. Este dado parece indicar que devem surgir alterações a nível de DNA quando a resistência à drogas ocorre em determinadas cepas de $S$. mansoni. A probabilidade de ocorrência de modificações genéticas globais, torna de interesse o uso de metodologia que permita análises de rearranjos genéticos globais. Vieira e cols ${ }^{22}$ estudando variações de populações brasileiras de $S$. mansoni conseguiram traçar um perfil genômico de vários isolados, relatando diferenças entre os isolados testados e diferenças individuais dentro de um mesmo isolado. Os autores observaram que as variações genômicas individuais entre populações naturais foi marcante, sendo mais significante do que aquela observada em parasitas que são mantidos no laboratório por várias gerações, entretanto não conseguiram iclentificar um marcador para resistência.

No presente trabalho foi possivel demonstrar diferença de resposta terapêutica entre os 10 isolados de $S$. mansoni provenientes de pacientes tratados e que continuaram a eliminar ovos nas fezes e um isolado proveniente de caramujos naturalmente infectados. Todavia não foi possível demonstrar resistência às drogas administradas, na infecção experimental de camundongos. A análise dos perfis de amplificação de DNA obtidos com os isolados em estudo, demonstrou baixo grau de variabilidade intraespecífica da espécie não sendo encontrados polimorfismos característicos que permitissem distinguir isolados obtidos de pacientes não curados, moluscos naturalmente infectados ou a cepa de referência LE.

Estudos de isolados provenientes de pacientes tratados e não curados serão realizados posteriormente, usando-se RNA como um possível marcador genético de resistência à drogas.

\section{SUMMARY}

Ten inbabitants of Itaquara, Babia, Brazil treated with oxamniquine and subsequently 
Araújo N, Souza CP, Passos LKJ, Simpson AJG, Dias Neto E, Pereira TR, Cerutti Júnior C, Alencar FEC, Dietze $R$, Katz $N$. Suscetibilidade aos agentes quimioterápicos de isolados de Schistosoma mansoni oriundos de pacientes tratados com oxaminiquine e praziquantel e não curados. Revista da Sociedade Brasileira de Medicina Tropical 29:467-476, set-out, 1996.

praziquantel were not cured. Schistosoma mansoni isolates derived from these patients were studied. Snails were infected with miracidia derived from the feces of these patients and the cercariae produced used to infect albino mice. The animals were then treated with a single oral dose of oxamniquine (25, 50 and $100 \mathrm{mg} / \mathrm{kg}$ ) or praziquantel $(100,200$ and $400 \mathrm{mg} / \mathrm{kg}$ ). The response to chemotherapy was significantly different in some of the isolates although it was not possible to characterize any of them as resistant. In addition, DNA analysis of the isolates by means of "Random Amplified Polymorfbic DNA "indicated a low degree of variability as compared with a laboratory strain, LE. Thus, it was not possible to characterize these organisms at a genetic level as a distinct strain.

Key-uords: Schistosoma mansoni. Strains. Susceptibility.

\section{REFERÊNCIAS BIBLIOGRÁFICAS}

1. Araújo N, Katz N, Dias EP, Souza CP. Susceptibility to chemotherapeutic agents of strain of Schistosoma mansoni isolated from treated and untreated patients. American Journal of Tropical Medicine and Hygiene 29:890-894,1980.

2. Barral V, This P, Imbert-Estabelet $D$, Combes $C$, Delseny $M$. Genetic variability and evolution of the Schistosoma genome by using random amplified polymorphic DNA markers. Molecular and Biochemical Parasitology 59:211-222, 1993.

3. Brindley PJ, Health S, Waters AP, Mccatchan TF, Sher A. Characterization of a programmed alteration in an $18 \mathrm{~S}$ ribosomal gene that accompanies the experimental induction of drug resistance in Scbistosoma mansoni. Proceedings of the National Academy of Science of the United States of America 88:7754-7758, 1991.

4. Coles GC, Bruce JI, Kinoto GK, Mutahi WT, Dias EP, Katz N. Drug resistance in Schistosomiasis. Transactions of the Royal Society of Tropical Medicine and Hygiene 80:347, 1986.

5. Dias LCS, Pedro RJ, Rigo E, Goto MMF, Mafra GL. Linhagem humana de Schistosoma mansoni resistente a esquistossomicidas. Revista de Saúde Pública 12:110, 1978.

6. Dias LCS, Pedro RJ, Deberaldini ER. Use of praziquantel in patients with Schistosomiasis mansoni previously treated with oxamniquine and/or hycanthone; resistance of Scbistosoma mansoni to schistosemicidal agents. Transactions of the Royal Society of Tropical Medicine and Hygiene 76:652-659, 1982.
7. Dias Neto E, Souza CP, Rollinson D, Katz N, Pena SDJ, Simpson AJG. The random amplification of polymorphic DNA allows the identification of strains and species of schistosome. Molecular and Biochemical Parasitology 57:83-88, 1993 a.

8. Dias Neto E, Steindel M, Passos LKJ, Souza CP, Rollinson D, Katz N, Romanha AJ, Pena SDJ, Simpson AJG. The use of RAPDs for the study of genetic diversity of Schistosoma mansoni and Trypanosoma cruzi.In: Pena SDJ, Chakraborty R, Epplen JT, Jeffreys AJ (eds) DNA Fingerprinting: State of the science. Birkhauser Verlag Basel Switzerland, p. 339-345. 1993b.

9. Drescher KM, Rogers EJ, Bruce JI, Katz N, Dias LCS, Coles GC. Response of drug resistant isolates of Schistosoma mansoni to antischistosomal agents. Memórias do Instituto Oswaldo Cruz 88:89-95, 1993

10. Fallon GP, Doenhoff MI. Drug Resistant Schistosomiasis: Resistance to praziquantel and oxamniquine induced in Schistosoma mansoni in mice is drug specific. American Journal of Tropical Medicine and Hygiene 51:83-88, 1994

11. Fulford AJC, Yeang F. Analysis of worm burden in experimental Schistosomiasis. Parasitology 97:308-315, 1988.

12. Katz N, Dias EP,Araújo N, Souza CP. Estudo de uma cepa humana de Schistosoma mansoni resistente aos agentes esquistossomicidas. Revista da Sociedade Brasileira de Medicina Tropical 6:381387,1973

13. Katz N, Rocha RS, Souza CP, Coura Filho P, Bruce JI, Coles GC, Kinoti GK. Efficacy of alternanting therapy with oxamniquine and praziquantel to treat Schistosoma mansoni in children following failure of first treatment. American Journal of Tropical Medicine and Hygiene 44:509-512, 1991.

14. Kaukas A, Dias Neto E, Simpson AJG, Southgate VR, Rollinson D. A phylogenetic analysis of Scbistosoma baematobium group species based on randomly amplified polymorphic DNA. International Journal of Parasitology 24:285-290, 1994.

15. Kemp HA, Hunter GW, Wilkins OP, Smalley H, Dashiell MA. Some ointments examined for protection against Schistosoma mansoni cercariae in preliminary tests. Military Medicine 119:1-10, 1956.

16. Martin GB, Williams JGK, Tanskley SD. Rapid identification of markers linked to Pseudomonas resistance gene in tomato by using random 
Araújo N, Souza CP, Passos LKJ, Simpson AJG, Dias Neto E, Pereira TR, Cerutti Jünior C, Alencar FEC, Dietze R, Katz N. Suscetibilidade aos agentes quimioterápicos de isolados de Schistosoma mansoni oriundos de pacientes tratados com oxaminiquine e praziquantel e não curados. Revista da Sociedade Brasileira de Medicina Tropical 29:467-476, set-out, 1996.

primers and near isogenic lines. Proceedings of the National Academy of Science of the United States of America 88:2336-2340, 1991.

17. Paran L, Kesseli R, Michelmore R. Identification of restriction fragment length polymorphic DNA markers linked to downy mildew resistance genes in lettuce, using near isogenic lines. Genome. 34:1021-1027, 1991.

18. Pellegrino J, Katz N. Experimental Chemotherapy of Schistosomiasis mansoni. Advances in Parasitology 6:233-290, 1968.

19. Santos FR, Pena SDJ, Epplen JT. Genetic and populational study of an Y-linked tetranucleotide repeat DNA polymorphism. Human Genetics 90:655-656, 1993.

20. Snedecor GW, Cochran WG. Statistical Methods 6th ed. Iowa, Iowa University Press. 1977.

21. Simpson AJG, Sher A, Mccutchan TE. The genome of Schistosoma mansoni: isolation of DNA, its size, bases and repetitive sequences. Molecular Biochemical Parasitolology 6:125-137, 1982.

22. Vieira LQ, Correa-Oliveira R, Katz N, Souza CP, Carvalho OS, Araújo N, Sher A, Brindley PJ. Genomic variability in field populations of Scbistosoma mansoni in Brazil as detected with a ribosomal gene probe. The American Journal of Tropical Medicine and Hygiene 44:69-78, 1991.

23. Welsh J, Mcclelland M. Fingerprinting genomes using PCR with arbitrary primers. Nucleic Acids Research 18:7213-7218, 1990.

24. Williams JGK, Kubelik AR, Livak KJ, Rafalski JA, Tingey SV. DNA polymorphisms amplified by arbitrary primers are useful as genetic markers. Nucleic Acids Research 18:6531-6535, 1990.

25. Yeang FSH, Marshall I, Huggins M. Oxamniquine resistance in Schistosoma mansoni: fact or fiction? Annals of Tropical Medicine and Hygiene 81:337-339, 1987. 